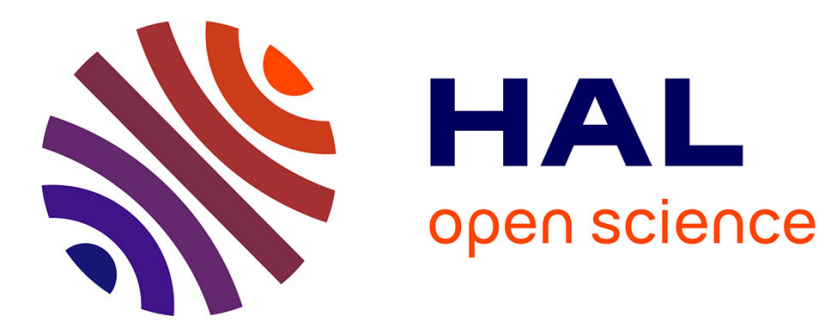

\title{
Spatial constraints for 3D perception in Helmet-Mounted Displays
}

Anne-Emmanuelle Priot, Charbonneau Marie, Paillé Damien

\section{To cite this version:}

Anne-Emmanuelle Priot, Charbonneau Marie, Paillé Damien. Spatial constraints for 3D perception in Helmet-Mounted Displays. Conference on Head-and-Helmet-Mounted Displays XIII - Design and Applications, 2008, United States. pp.69550G, 10.1117/12.790387 . hal-00686063

\section{HAL Id: hal-00686063 https://hal.science/hal-00686063}

Submitted on 6 Apr 2012

HAL is a multi-disciplinary open access archive for the deposit and dissemination of scientific research documents, whether they are published or not. The documents may come from teaching and research institutions in France or abroad, or from public or private research centers.
L'archive ouverte pluridisciplinaire HAL, est destinée au dépôt et à la diffusion de documents scientifiques de niveau recherche, publiés ou non, émanant des établissements d'enseignement et de recherche français ou étrangers, des laboratoires publics ou privés. 


\title{
Spatial constraints for 3D perception in Helmet-Mounted Displays
}

\author{
Anne-Emmanuelle Priot*a ${ }^{\mathrm{a}}$, Marie Charbonneau ${ }^{\mathrm{b}} \&$ Damien Pailléc \\ ${ }^{a}$ Département de Sciences Cognitives, Institut de Médecine Aérospatiale du Service de Santé des \\ Armées (IMASSA), BP 73, 91223 Brétigny-sur-Orge cedex, France; \\ ${ }^{\mathrm{b}}$ THALES Aerospace, rue Toussaint-Catros, 33187 Le Haillan cedex, France; \\ ${ }^{c}$ ESSILOR, Service Vision, 57 avenue de Condé, 94106 Saint-Maur-des Fossés cedex, France
}

\begin{abstract}
Distance judgments in virtual environments and Head-mounted Displays (HMD) systems are generally underestimated compared with judgments in the real world. Some visual depth cues may be absent or modified, according to the technology used.

After a brief review of the literature pertaining to the representation of depth in Helmet-Mounted Displays, we explore two possible causes for the reduced distance perception in virtual environments: the increased interocular separation (or hyperstereopsis) and the reduction of the field of view.

Some laboratory and training ground data are reported. The effective influence of each factor on space perception is discussed.
\end{abstract}

Keywords: Helmet-Mounted Displays, field of view, hyperstereopsis, depth perception

\section{INTRODUCTION}

Multiple and redundant visual cues for the perception of the three-dimensional space perception are available when exploring a natural scene. The visual cues to depth may be monocular and/or binocular. Some are quite independent from visual signal processing and directly depend on the optical parameters of the eye. Other visual cues for three-dimensional space perception demand a visual processing of the light signal.

Under normal conditions, the integration of those information leads to a single, coherent, three-dimensional and nearly metric perception of space ${ }^{1}$. In virtual environments, perceived egocentric distances tend to be underestimated when compared to the same distance judgments in the real world. This underestimation may reach $47 \%$ of the true distance ${ }^{2,3}$, thereby impacting the ability for a user to interact in the virtual world as in the real one.

In a virtual environment, most but not all the relevant visual cues to depth are present in accordance with the technology used. Some hypotheses concerning two factors affecting depth perception are discussed in the following section.

\section{LITTERATURE DATA}

Depth perception can be defined in two different ways: the relative (exocentric) distance measured between two points in the environment, and the absolute (egocentric) distance measured from the observer to a point in the environment ${ }^{4}$.

One possible candidate to the explanation of distance underestimation is the size of the field of view. Actually, the projection technologies (HMD or projection screen) restrict the visual field to a central part of the human natural visual field (which is approximately $200^{\circ}$ Horizontal by $120^{\circ}$ Vertical). The observation of a virtual image may be considered as the observation of a scene through a window reducing the number of objects that can be simultaneously seen in the scene and thus limiting the chances of a correct understanding of the environment ${ }^{5}$.

*apriot@imassa.fr; phone: +(33) 169237251; fax: +(33) 169238186 
Despite the fact that the size of the field of view has been reported to play a crucial role on the space perception in real environment ${ }^{6,7}$, its effective role in virtual environment needs to be clarified.

Another parameter that could impact distance perception in stereoscopic displays may be the particular demand placed on the vergence system. With See-through Helmet-Mounted Displays, images intensifiers tubes are located on the side of the helmet. This optically increases the inter-ocular separation. Horizontal binocular disparities and the required vergence to fuse on close object are increased. According to the form of the telestereoscopic device used and to the observation distance, subjects perceive objects closer and/or strengthened in depth. Many studies shown that vergence cues play an important role in egocentric distance perception within the "prehension space" of the hand, in a reduced cue environment ${ }^{8,9,10}$. The amount of differential perspective (pattern of vertical disparities) which provides information about the absolute distances to objects in the scene is also increased ${ }^{11}$.

\section{FIELD OF VIEW (FOV)}

The experiments reported below deal with absolute distances in the personal space $(<1 \mathrm{~m}){ }^{1}$, which are especially relevant to many virtual environments applications.

Among the relevant cues partially represented in a virtual environment, is the size of the visual field. Some experiments reported that the truncation of the visual field, for example in peephole views of the real world, causes compression of perceived distance - people think things are closer than they actually are ${ }^{12}$. The missing part of the space could provide additional data for the distance estimation task to objects in the environment. In the real world, it has been shown that the overlap of peripheral and fovea information is necessary for veridical perception to occur and that restricting the field of view will interfere with both perception and visuomotor performance ${ }^{6}$.

The purpose of the experiment was to test the influence of the size of the FOV on the perception of the proximal egocentric distance in a simulated real world environment.

\subsection{Material and methods}

\subsubsection{Subjects}

Ten subjects, aged between 20 and 48, were involved, seven men and three women (mean age 28.4 years). Subjects were self-declared volunteers for the study and were naïve as to its purpose. Each of them had normal uncorrected acuity or was within range of the \pm 4 dioptres included in the incorporated focal adjustment of the Head-Mounted Display (HMD). Their stereoscopic vision was tested; none of the observers presents perceptual suppression phases (determined by the TNO test, plate IV). All had perifoveal stereoacuity of $30 \mathrm{~s}$ or better (determined by the TNO test, plates V, VI and VII) and a central stereoacuity of 9/9 (determined by the Titmus Circles test).

\subsubsection{Apparatus}

The subjects were seated in a real car cockpit. The environment was fully lit so that the observer could see the whole dashboard. The virtual environment was displayed using a Head-Mounted Display (HMD) 120/40. The HMD was equipped with a LaserBIRD optical Tracker returning, in real time, the exact position of the observer's eyes in order to reproduce the exact point of view of each observer in the real car.

The stimuli used were static 1280x1024 pixels snap shots of the exact replica of the real cockpit seen from the point of view of the observer. They were displayed thanks to two PCs equipped with nVidia GeForce 4 based graphics board and linux OS. Each image, the heading and pitch of the virtual observer were varied, changing the direction of the visual axis in order not to present always the same image. One object of the scene was designated as target, namely the steering wheel (a torus of $38 \mathrm{~cm}$ diameter).

Three different FOV were tested: $60^{\circ}, 90^{\circ}$ and $120^{\circ}$. The $60^{\circ}$ and $90^{\circ}$ horizontal FOV were restricted by the image rendering software by adding black masks each side of the global image. 


\subsubsection{Procedure}

The goal of the present study was to test whether a sufficient amount of information out of the target allows a correct estimation of distance. The phase was divided into three distinct sessions. Each session was made with a different FOV: $60^{\circ}, 90^{\circ}$ and $120^{\circ}$. The results concerning the $90^{\circ}$ and $120^{\circ} \mathrm{FOV}$ are not reported here as they are similar to those from $60^{\circ} \mathrm{FOV}$. For each FOV, we tested distance estimation to the steering wheel with three different amounts of information out of the target (corresponding to three distances to the steering wheel). In the first part, with a $60^{\circ} \mathrm{FOV}$, the subjects were successively seated at three different distances from the middle of the steering wheel: $39,50,60 \mathrm{~cm}$ corresponding respectively to $10^{\circ}, 20^{\circ}$ and $26^{\circ}$ of the field of view filled by information out of (around) the target (Table 1).

\begin{tabular}{|l|l|l|}
\hline FOV & $60^{\circ}$ \\
\hline & $\begin{array}{l}\text { Distance to the steering } \\
\text { wheel }\end{array}$ & $\begin{array}{l}\text { Amount of information out } \\
\text { of the target }\end{array}$ \\
\cline { 2 - 3 } $39 \mathrm{~cm}$ & $10^{\circ}$ \\
\hline $50 \mathrm{~cm}$ & $20^{\circ}$ \\
\hline $60 \mathrm{~cm}$ & $26^{\circ}$ \\
\hline
\end{tabular}

Table 1: distance to the steering wheel with correspondent field of view filled by information out of the target.

Subjects sat in the adjustable cockpit at one of the three distances. Their position to the middle of the steering wheel was displayed on the control screen and was adjusted by sliding the seat. Before starting the experiment, a calibration phase took place as in the first experiment

First the subjects had to explore the real visual scene without any constraints. They were told not to touch the real environment and to keep their hand on their knee during the experiments. Then they adjusted the HMD on their head and were told to close their eyes before the beginning of the experiment. The start of a trial was given by the experimenter that told the subjects to open their eyes once the first image was displayed. Three different kinds of images were randomly presented to the observer: 1) the virtual scene and the real scene correspond; 2) the virtual scene is translated $\Delta \mathrm{cm}$ towards the observer; and 3) the virtual scene is translated $\Delta \mathrm{cm}$ away the observer ( $\Delta$ was fixed to $2.5 \mathrm{~cm}$ after a JND test). The subjects had then to verbally compare the egocentric distance to the virtual and real steering wheel by a forced-choice method: is the objects closer, equal, or farther compared to the reality? Once the task done, the experimenter asks the subjects to raise the HMD and look at the real scene for a few seconds. During this time, the experimenter modifies the parameters of the virtual scene, and then asked the observer to look at the next image. For each distance 9 images were displayed. As there were three distances for each FOV and three FOV were tested, each observer was presented 81 images.

\subsection{Results}

The data of all the subjects were gathered and, for each size of FOV, and each distance, the comparison between the virtual and the actual distance to the steering wheel were plotted in histogram form. Figure 1 presents the result for $60^{\circ}$ FOV and the three distances from the steering wheel.

When the subject is sat $39 \mathrm{~cm}$ from the steering wheel, corresponding to an amount of information out of the target of $10^{\circ}$, he underestimates the distance to the target since the results are shifting to "close" response (figure 1). While when he sat at $50 \mathrm{~cm}$ and $60 \mathrm{~cm}$ (corresponding to an amount of information out of (around) the target of $20^{\circ}$ and $26^{\circ}$ ), the results are centered on "equal response": the perception of the egocentric distance to the virtual target corresponds to its perception in the real world. When the subject is sat $50 \mathrm{~cm}$ from the steering wheel, the target occupies the two-thirds $(2 / 3)$ of the image, thus one third (1/3) of the image is filled by information out of the target. A statistical Pearson's chisquare showed a significant difference between the data obtained at $39 \mathrm{~cm}$ from the steering wheel and those at $50 \mathrm{~cm}$ $(\mathrm{p}<0.05)$. Idem for the results obtained at $39 \mathrm{~cm}$ from the steering wheel and those at $60 \mathrm{~cm}(\mathrm{p}<0.05)$. But there is no significant difference between the data obtained at $50 \mathrm{~cm}$ and those at $60 \mathrm{~cm}(\mathrm{p}=0.66)$. 


\section{Percentage of response in function FOV $60^{\circ}$ of the amount of information available out ouf the target}

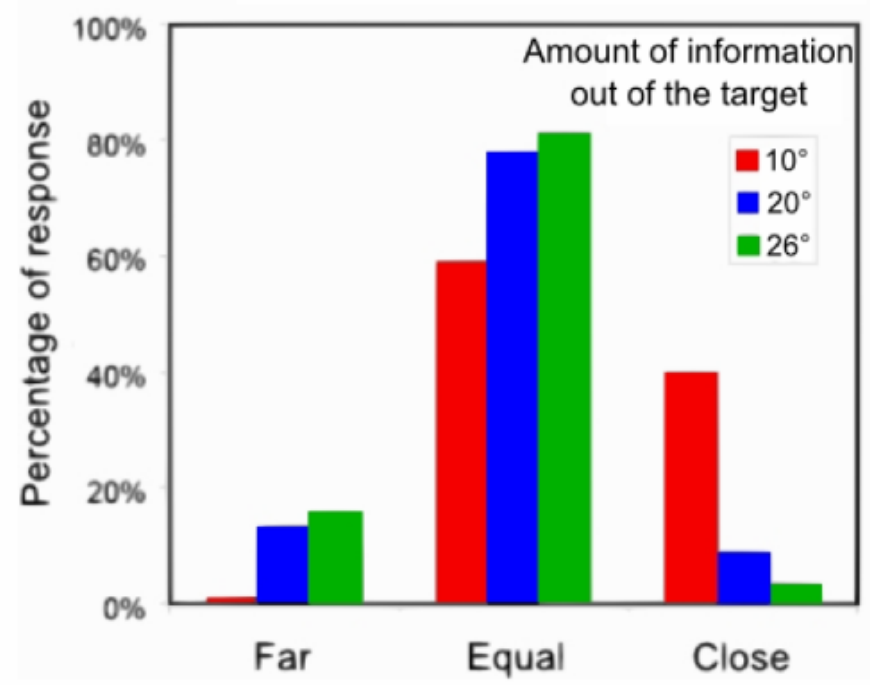

Figure 1: percentage of responses as a function of the size of field of view out of the target for the $60^{\circ}$ FOV image.

\subsection{Discussion}

This experiment that involved stationary observers was designed to investigate how the size of the FOV may affect the accuracy of egocentric distance judgments to nearby objects. Our intent was to determine whether the size of the FOV would affect egocentric distance estimation to nearby objects in a static simulated rich environment compared to a real non-limited environment.

The results show that when the amount of information out of the object is below a threshold neighboring the third (1/3) of the image, whatever the size of the field of view is, egocentric distance judgments tend to be underestimated. Egocentric distance estimation seems to be linked to the ratio between the angular size of the target and the angular size of the field of view. Such conditions occurred rarely during flight operations.

\section{LATERAL SENSOR PLACEMENT AND STEREOPSIS}

Both binocular disparities and convergence are sensitive to the placement of the sensors in a stereoscopic display and could be modified in See-through or type II Helmet-Mounted Displays. Increasing inter-sensors distance (hyperstereo vision) is a candidate factor for depth perception modification.

In fact, sensors placement was found to influence the pilots' estimation of distance. Data on hyperstereo effect come from lab studies as well as flight testing and pilot training. Results reported here involve both absolute and relative distance perception and the range of distances explored extends up to action space $(<30 \mathrm{~m})$ and vista space $(>30 \mathrm{~m}){ }^{1}$, which are relevant for many flight operations.

A simulation study used videotapes recorded during helicopter flights with varying the layout of a couple of cameras, modifying the inter-camera separation and the convergence state of their optical axis ${ }^{13}$. Both objective and subjective data were obtained. Depth perception was evaluated using a double distance paradigm. Results showed a relative 
underestimation of the first plane (egocentric distance to the marker) compared to the further plane (relative distance between the marker and the target) for short and mid distances ( $295 \mathrm{~m}$ for distance and $60 \mathrm{ft}$ for height). The estimations were significantly dependant on the spatial arrangement of the cameras. The results also individualized a clear subjects' preference for the reproduction of the three dimensions of the over flown terrain at low altitude. This condition was obtained with an increased inter-camera separation $(240 \mathrm{~mm})$ and convergence of the optical axis of the video cameras (convergence at $20 \mathrm{~m}$ ). These observation conditions enhanced depth perception due to magnified direct and crossed lateral binocular disparities.

It seems unlikely that increased convergence would have an effect at the distances investigated. Nevertheless, lateral retinal disparities may provide depth information up to $264 \mathrm{~m}$ according to Boff and Lincoln ${ }^{14}$. We could suppose that the range of distances where binocular disparity acts as a cue for depth perception increases with greater inter-sensors separation.

French developmental testing for the earlier configuration of the TopOwl ${ }^{\text {TM }}$ HMD (Thales Visionics See-Through HMD) with approximately four-folded greater-than normal Inter-Pupillary Distance was conducted on a two year period from 1995 to 1997. Leger et al. reported a systematic underestimation of distances and heights ${ }^{15}$.

A prospective study following Tiger Helicopter pilots' training (figure 2) showed double height estimation errors with a tendency for the pilot to stand farther from the target. Such effect occurred for heights smaller than $100 \mathrm{ft}^{16}$. Pilots also underestimated double distances $(<180 \mathrm{~m})$. Landing was often cited as the most delicate situation encountered. Several pilots cited landing as the most delicate situation encountered. Main contributing factors were difficulties with height estimation near the ground and lack of experience with the TopOwl ${ }^{\mathrm{TM}}$ HMD. Some other studies highlighted terrain slopes as an aggravating factor ${ }^{17}$.

\section{Height and distance relative errors $\quad \square$ Height as a function of training $\quad \square$ Distance}

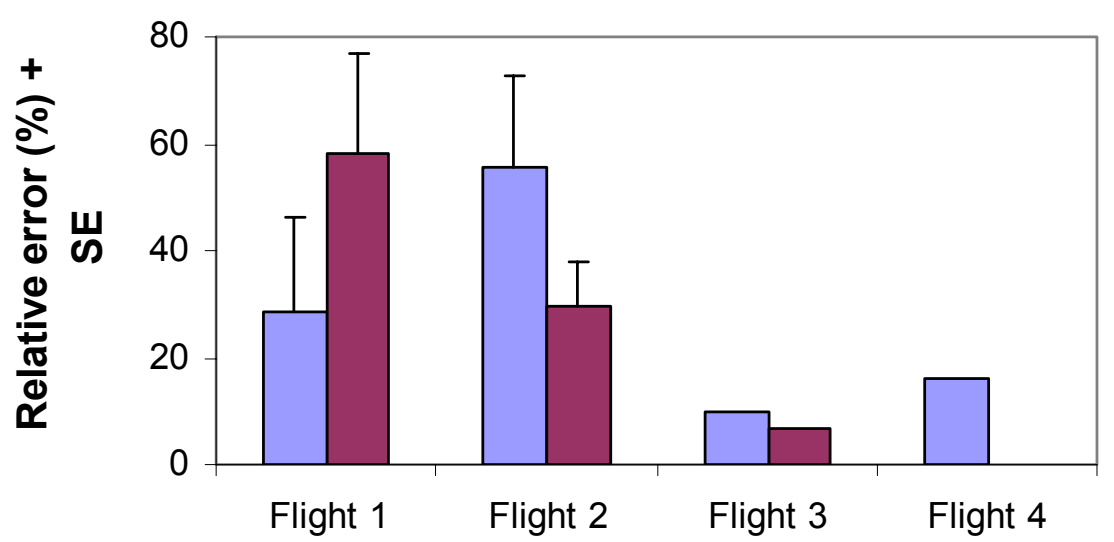

Fig 2: Height and distance relative errors as a function of training (in flight number). Height relative error $=($ estimated height - actual height)/actual height. Relative errors are expressed in percentages (relative error x100). Height (or distance) values are $\mathrm{H}$ (or D) values and have to be doubled to obtain $2 \mathrm{H}$ (or 2D) values. $\mathrm{n}=15$ (flight 1), $\mathrm{n}=4$ (flight 2), $\mathrm{n}=1$ (flight $3 \& 4$ ).

Hyper stereo effects are complex and depend on many factors such as observation distance or the presence of many visual cues for distance. 
Although the distance over which vergence might provide useful depth information is limited to personal space, binocular disparity cue may be efficient up to longer observation distance. Flanagan et al. showed that vergence and differential perspective are ineffective at $6 \mathrm{~m}^{18}$. Hyperstereo effect on egocentric distance perception might be effective at very closed distance. But hyperstereo effect might impact relative distance perception for longer observation distance.

\section{CONCLUSION}

There's no consensus in literature that may explain the compression of absolute egocentric distance judgments in virtual environments. We here discussed the way that a limited field of view (FOV) and lateral sensor placement contribute to the modification in depth perception.

Pilots may maneuver within reduced-cued environment. The relative weight of visual cues for space perception also depends on individual factors, which define the observer's cognitive style. For all these reasons, literature data regarding laboratory studies may be not directly transposable to predict real visual perception of the pilot wearing a HelmetMounted Display.

\section{ACKNOWLEDGMENTS}

Data presented in section 3 were obtained during a $\mathrm{PhD}$ thesis in collaboration between Laboratoire de Physiologie de la Perception et de l'Action, CNRS-Collège de France and Technical Centre for Simulation, Renault Technocentre.

\section{REFERENCES}

[1] J. E. Cutting, "High-Performance computing and Human vision I," Behavior Research Methods, Instruments \& Computers, vol. 29, 27-36 (1997).

[2] B. G. Witmer, and P. B. Kline, "Judging perceived and traversed distance in virtual environments," Presence: Teleoperators \& Virtual Environments, vol. 7, 144-167 (1998).

[3] D. R. Lampton, D. P. McDonald, M. Singer et al., "Distance estimation in Virtual Environments," in Human Factors and Ergonomics Society 39th Annual meeting, Santa Monica, CA, 1268-1272 (1995).

[4] J. M. Foley, "Binocular Space Perception," Binocular Space Perception, 75-92, London (1991).

[5] H. Dolezal, Living in a world transformed: Perceptual and performatory adaptation to visual distorsion, New York: Academic Press (1992).

[6] P. L. Alfano, and G. F. Michel, "Restricting the field of view: perceptual and performance effects," Percept Mot Skills, vol. 70, no. 1, 35-45 (1990).

[7] S. J. Watt, M. F. Bradshaw, and S. K. Rushton, "Field of view affects reaching, not grasping," Experimental Brain Research. Experimentelle Hirnforschung. Experimentation Cerebrale, vol. 135, no. 3, 411-416 (2000).

${ }^{[8]}$ A. Viguier, G. Clement, and Y. Trotter, "Distance perception within near visual space," Perception, vol. 30, no. 1, 115-124 (2001).

[9] M. Mon-Williams, and J. R. Tresilian, "Some recent studies on the extraretinal contribution to distance perception," Perception, vol. 28, no. 2, 167-181 (1999).

${ }^{[10]}$ J. R. Tresilian, M. Mon-Williams, and B. M. Kelly, "Increasing confidence in vergence as a cue to distance," Proc Biol Sci, vol. 266, no. 1414, 39-44 (1999).

[11] B. J. Rogers, "Depth and distance scaling under telestereoscopic viewing: The roles of vergence and differential perspective," Perception, vol. 32 ECVP Abstract supplement (2003).

[12] M. A. Hagen, R. K. Jones, and E. S. Reed, "On a neglected variable in theories of pictorial perception: truncation of the visual field," Percept Psychophys, vol. 23, no. 4, 326-30 (1978).

[13] C. Roumes, J. Plantier, and A. Leger, "Perception of distance in a binocular helmet-mounted display: data from helicopter in-flight video tapes," in Helmet-Mounted Displays III, 66-70 (1998). 
[14] K. R. Boff, and J. E. Lincoln, Engineering data compendium: Human perception and performance, WrightPatterson-OH: Armstrong Aerospace Medical Research Lab (1988).

[15] A. Leger, C. Roumes, J. M. Bergeaud et al., "Flight testing of a binocular bisensor HMD for helicopter: some human factors aspects," in Helmet-Mounted Displays III, 136-143 (1998).

[16] A. E. Priot, S. Hourlier, E. Barbarat et al., "Adaptation to increased interocular distance: survey of Tiger pilots training," in HFM-141 Symposium on "Human factors and medical aspects of day/night all weather operations: current issues and future challenges", Heraklion (2006).

[17] M. E. Kalich, C. E. Rash, W. E. McLean et al., "A limited flight study for investigating hyperstereo vision," in Head- and Helmet-Mounted Displays XII: Design and Applications, 65570I (2007).

${ }^{[18]}$ P. Flanagan, G. W. Stuart, and P. Gibbs, "Hyperstereopsis in helmet-mounted NVDs: absolute distance perception," in Head- and Helmet-Mounted Displays XII: Design and Applications, 65570J (2007). 